\title{
CHANGES OF BODY COMPOSITION AMONG UNIVERSITY STUDENTS DEPENDING ON THE CONSUMPTION FREQUENCY OF SELECTED BAKERY PRODUCTS
}

\author{
Martina Gažarovál, Lucia Mečiarovál, Silvia Meňhartovál, Maroš Bihari ${ }^{l}$
}

${ }^{1}$ Slovak University of Agriculture, Faculty of Agrobiology and Food Resources, Department of Human Nutrition, Tr. A. Hlinku 2, 94976 Nitra, Slovak Republic

\begin{abstract}
Background. Bakery products such as bread, rolls, croissants and others are an important part of eating habits. Recently, their consumption has been associated with an undesirable increase and prevalence of overweight or obesity.

Objective. The aim of the work was to analyze the influence of the consumption frequency of selected types of bread/ bakery products on anthropometric parameters in a group of university students.

Material and Methods. The group was composed of 120 volunteers consuming different types of bread / bakery products with different consumption frequencies during the week. The anthropometric parameters were measured by InBody 720 . To obtain information on the frequency of consumption we used the questionnaire method.

Results. The results suggest that in most cases it is not the type of product that is decisive, but its quantity consumed and frequency of consumption supported by low daily physical activity, resp. sedentary lifestyle. We found similar results of the influence of the consumption frequency on anthropometric parameters for all types of bread. Low levels of physical activity, basal metabolism and consumption of selected types of bakery products (wheat bread, wheat rolls, sweet pastries and gluten-free variants) can cause an increase in visceral as well as total body fat, weight gain, BMI, at the expense of fat-free mass. Our results showed that the groups of participants who did not consume a certain type of bread at all, rarely or 1 to 3 times a week, showed higher values of the examined parameters (BMI, body weight, body fat percentage, WHR) compared to the group which consumed a particular type of bakery products on average 4 to 7 times a week. The parameter's values were largely influenced by the levels of physical activity.

Conclusions. Based on the results it is possible to assume that if the bakery products are the part of a balanced diet with regard to the individual energy needs, it should not be the main cause of overweight / obesity in humans.
\end{abstract}

Key words: bakery products, pastry, anthropometry, obesity, health, body fat

\section{INTRODUCTION}

Adult feeding patterns are rooted from childhood experiences. Household healthy food availability and accessibility have been positively associated with healthful meal intake in youth. Modelling of healthful dietary patterns by parents and friends may promote healthy eating among children and adolescents [12,29]. As people age, they should implement healthy eating to maintain an ideal body weight, since both overweight and underweight lead to increased morbidity and mortality [25]. Fast food is very popular among young people, as well as fast consumption of large portions of unhealthy foods and high intake of sweetened drinks combined with average physical activity. The potential risk is also posed by night eating, snacking, and alcohol consumption [3,5,15,51].
Quality food high in proteins, vitamins and minerals, but low in cholesterol, saturated fat, and especially trans-fat should be recommended for weight maintenance. People should consume more of the nutrient-dense whole-grain foods, whole-wheat breads, and whole-grain cereals to meet carbohydrate needs and the consumption of refined foods (white bread, pasta, and other refined products) should be limited [25]. Whole-grains are the key components of healthy eating habits. Thanks to their low energy density and satiating effects are responsible for their potential role in weight control [22,37,50]. Current trends in diet suggest a slight decline in the consumption of bread and traditional bakery products due to concerns about the growing body weight of consumers. It is thanks to this belief that bread is cursed and excluded from many dietary patterns and

Corresponding author: Martina Gažarová, Slovak University of Agriculture, Faculty of Agrobiology and Food Resources, Department of Human Nutrition, Tr. A. Hlinku 2, 94901 Nitra, Slovakia, phone: +421 37641 4210,e-mail: martina.gazarova@uniag.sk; martina. gazarova@gmail.com, https://orcid.org/0000-0001-8275-7311

(C) Copyright by the National Institute of Public Health NIH - National Research Institute 
replaced by other, relatively harmless and potentially healthier equivalents. Gluten-free eating behaviours have been in most cases perceived to be healthier than gluten-containing ones. However, the nutritional value and quality of gluten-free products is questionable. Consumption of gluten-free bread is usually associated with excessive energy, animal protein and fat intake and reduced intake of dietary fiber, magnesium and folic acid $[45,68]$. Gluten-free bread provides twice as much fat, mainly saturated fat in comparison to its equivalents with gluten $[2,8,17,45]$. In many cases, the fear of weight gain is justified, but with good eating habits, diet and principles of rational nutrition, but especially quantity, bread cannot be considered the primary cause of overweight or obesity, especially given the fact that bread consumption is declining worldwide, but the prevalence of obesity is rising [21].

Healthy eating plays a critical role in risk reduction for various disease states and helps to individuals lose excess fat mass. However, healthy eating must be accompanied by physical activity, proper sleep and adequate time for stress reduction $[35,40,47,56]$.

In practice, the most commonly used parameter to determine overweight or obesity is the body mass index. BMI is useful for the initial screening of the general population for classification of excess weight and it is employed as the anthropometric indicator of excess adiposity. It should be used to classify individuals as having overweight (BMI 25 to $29.9 \mathrm{~kg} / \mathrm{m}^{2}$ ) or obesity (BMI $\geq 30 \mathrm{~kg} / \mathrm{m}^{2}$ ), after taking into account age, gender, ethnicity, fluid status, and muscularity [20]. It is an indirect measure for estimation of total body fat mass. Using BMI as the primary screening tool for obesity and overweight is consistent with recommendations and guidelines developed by many societies and task forces [33,46,48]. However, BMI alone cannot identify excess adiposity and establish a diagnosis of overweight or obesity in all instances [52] and it does not provide accurate information on body fat distribution, so it is appropriate to supplement it with other indicators. The most common means of assessing central obesity are waist circumference and waist-to-height ratio [21] estimated the visceral adipose tissue and reflected a dysfunctional ability of adipose tissue in general to store fat with redistribution to intra-abdominal adipose tissue. The predictive value of waist circumference is generally independent of, and stronger than, BMI [20]. Other measurements of adiposity may be considered, too. Bioelectric impedance is commonly used but is dependent on the hydrational state of individuals [53].

The aim of the survey was to find out how frequency consumption of different kinds of bakery products have been able to influence selected risk factors for overweight or obesity among young adult, especially university students.

\section{MATERIALS AND METHODS}

\section{Characteristics of the participants}

One hundred and twenty volunteers - students studying at university - were included in the research. The average age of them was $23 \pm 1$ years. The requirement for participation was the consent of individuals with study and measurement conditions. Participants with the present severe disease or with recommended special dietary regimen were excluded prior to the start of the study.

\section{Dietary Assessment}

For study purposes questionnaire method was used to obtain information on frequency consumption of different kinds of bakery products. Each participant completed the questionnaire anonymously. We focused on consumption of wheat bread, wholegrain bread, wheat rolls, sweet pastries and glutenfree bakery products and asked how often the participants consume selected types of bread / bakery products. The options were either 4-7 times a week, 1-3 times a week, rarely or never. Accordingly, we divided the study participants into 4 groups. Part of the questionnaire was also to determine the level of physical activity. This part dealt with the form / type of physical activity performed (aerobic or anaerobic), the length of one exercise process in minutes, the number of days practiced per week and the number of months / years devoted to regular exercise. The main purpose of the research was to analyze the relationship (direct or indirect) between the frequency of consumption of individual types of bakery products and selected anthropometric parameters.

\section{Anthropometric measurements}

Body composition was diagnosed by multifrequency bioelectrical impedance analysis measuring the total impedance at frequencies of $1,5,50,100$, 500, $1000 \mathrm{kHz}$. We used InBody 720 (Biospace Co. Ltd., Seoul, Republic of Korea). Every participant was informed with the measurement procedure, the possible risks of measuring in the case of pregnancy or having an artificial pacemaker at the heart were explained. Before the measurement, participants were asked to excrete and refrain from drinking excessive amounts of water and signed an informed written consent for the measurement procedure and also agreed to the processing of personal data. The Lookin'Body 3.0 software was used to process the results. The following body composition parameters were measured: body mass index (BMI, $\left(\mathrm{kg} / \mathrm{m}^{2}\right)$, waist-to-hip ratio (WHR), physical condition (points), basal metabolic rate (BMR, kcal), fat-free mass (FFM, $\%$ ), visceral fat area $\left(\mathrm{VFA}, \mathrm{cm}^{2}\right)$, percentage of body fat (PBF, \%), intracellular water (ICW, \%), extracellular 
water (ECW, \%), total body water (TBW, \%). Body height was measured in a standing position without shoes on the electronical medical scales Tanita WB3000 .

\section{Statistical analysis}

Microsoft Office Excel 2010 (Los Angeles, CA, USA), XLSTAT (Version 2019.3.1) and STATISTICA $\mathrm{Cz}$ version 13 (TIBCO Software Inc., Palo Alto, California, USA) were used for statistical analysis. The changes between groups were evaluated using a one-way analysis of variance (ANOVA) followed by Tukey's post hoc test. The data were presented as the means \pm standard deviation (SD). The level of statistical significance was set as $P<0.05$. We used also Pearson's correlation analysis between parameters.

\section{RESULTS AND DISCUSSION}

The total number of volunteers who completed the anthropometric measurement was one hundred and twenty. Table 1 shows the baseline characteristics of the group. Variables were presented as mean with standard deviations. The mean values of the evaluated parameters were in the range of reference limits. The differences in the values of anthropometric parameters of individual groups according to the frequency of consumption of different types of bakery products are shown in Table 2 and Table 2a. Table 3 shows correlation between parameters.

The analysis results of the influence of the consumption frequency of white bread showed that those who avoid its consumption had the highest values of basal metabolism, but also of body weight, which was related to high values of visceral fat. Based on this, the highest BMI and WHR values were confirmed in this group of participants. Unexpectedly, we found the lowest proportion of total and visceral body fat in the group with regular consumption (4 to 7 times a week) of white bread. These consumers had the best fitness values, which was reflected in the highest values of fat-free mass and volume status. However, we did not find significant differences between the individual groups $(\mathrm{P}>0.05)$.

We found similar results when evaluating the effect of the frequency of consumption of whole-grain bread. Consumers with the most often consumption of whole-grain bread had the best condition based on physical activity. Good physical condition had a positive effect on fat-free mass and volume status, but a negative effect on BMI, as muscle mass had an effect on increasing its values. From the point of view of central obesity, whole-grain bread consumers with rarely consumption had the worst results. We found significant differences only in WHR $(\mathrm{P}<0.05)$.

In the case of wheat rolls, the body composition analysis revealed significant differences between the group that consumed this type of bakery products rarely and the group with the most frequent consumption $(\mathrm{P}<0.05)$. The highest values of condition and basal metabolism, as well as fat-free mass and volume status were found in the group with the consumption of wheat rolls 4-7 times a week. We found the worst parameter values of fatness and indicators of obesity (VFA, PBF, WHR, BMI) mainly in the group with occasional consumption of wheat rolls and in the group avoiding their consumption.

Analysis of the effect of the consumption frequency of sweet pastry showed that the worst values of obesity indicators were in the group that consumed this type of pastry 1-3 times a week (VFA, PBF, WHR, BMI). Paradoxically, we found the best results of the mentioned parameters among the participants with regular consumption. In the case of VFA and PBF, we found significant differences $(P<0.05)$. These differences were caused by a higher level of physical

Table 1. Baseline characteristics of body composition in study group

\begin{tabular}{|l|c|c|c|c|c|c|}
\hline \multicolumn{1}{|c|}{ Parameters } & Mean & \pm SD & Max & Min & Mod & Med \\
\hline Age, years & 23 & 1 & 26 & 20 & 23 & 23 \\
\hline Height, cm & 169.1 & 8.7 & 200.0 & 150.8 & 168.0 & 168.8 \\
\hline Weight, $\mathrm{kg}$ & 65.0 & 13.3 & 115.1 & 46.1 & 64.7 & 61.7 \\
\hline Body mass index, kg/m ${ }^{2}$ & 22.6 & 3.2 & 31.9 & 17.0 & 22.8 & 22.1 \\
\hline Waist-to-hip ratio & 0.86 & 0.05 & 1.04 & 0.78 & 0.83 & 0.85 \\
\hline Condition & 76 & 7 & 108 & 59 & 72 & 75 \\
\hline Basal metabolic rate, kcal & 1418 & 247 & 2456 & 1019 & ND & 1353 \\
\hline Fat-free mass, \% & 74.6 & 6.7 & 91.4 & 58.3 & ND & 74.8 \\
\hline Visceral fat area, cm ${ }^{2}$ & 67.8 & 22.8 & 140.6 & 24.9 & 76.5 & 65.1 \\
\hline Percentage of body fat, \% & 25.4 & 6.7 & 41.6 & 8.5 & 29.6 & 25.2 \\
\hline Intracellular water, \% & 62.1 & 0.5 & 63.4 & 61.0 & 62.2 & 62.1 \\
\hline Extracellular water, \% & 37.9 & 0.5 & 39.0 & 36.6 & 37.8 & 37.9 \\
\hline Total body water, \% & 54.6 & 5.0 & 67.2 & 42.7 & ND & 54.8 \\
\hline
\end{tabular}




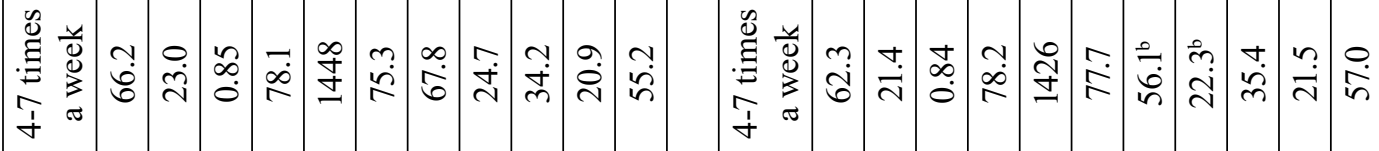

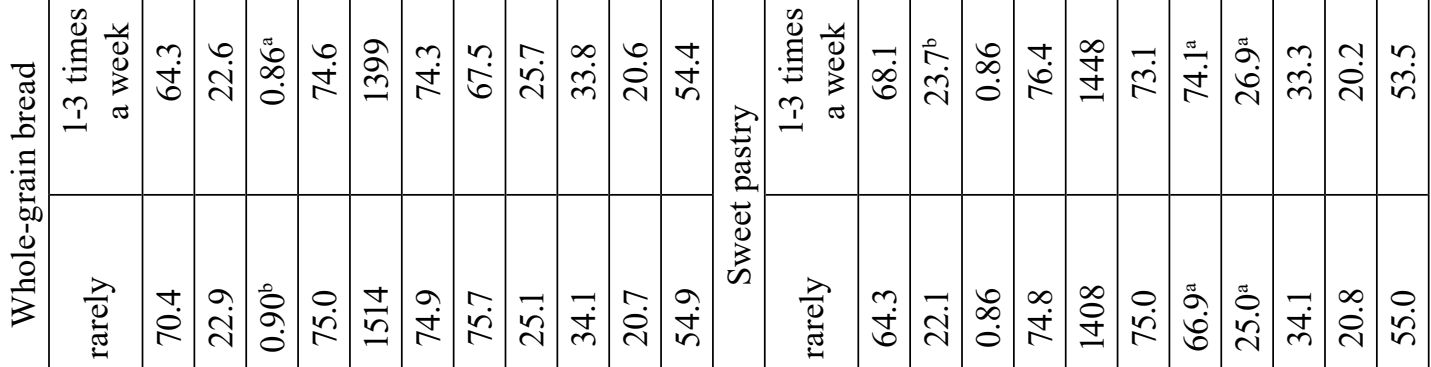

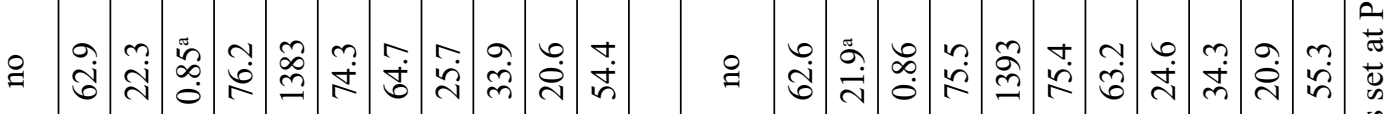

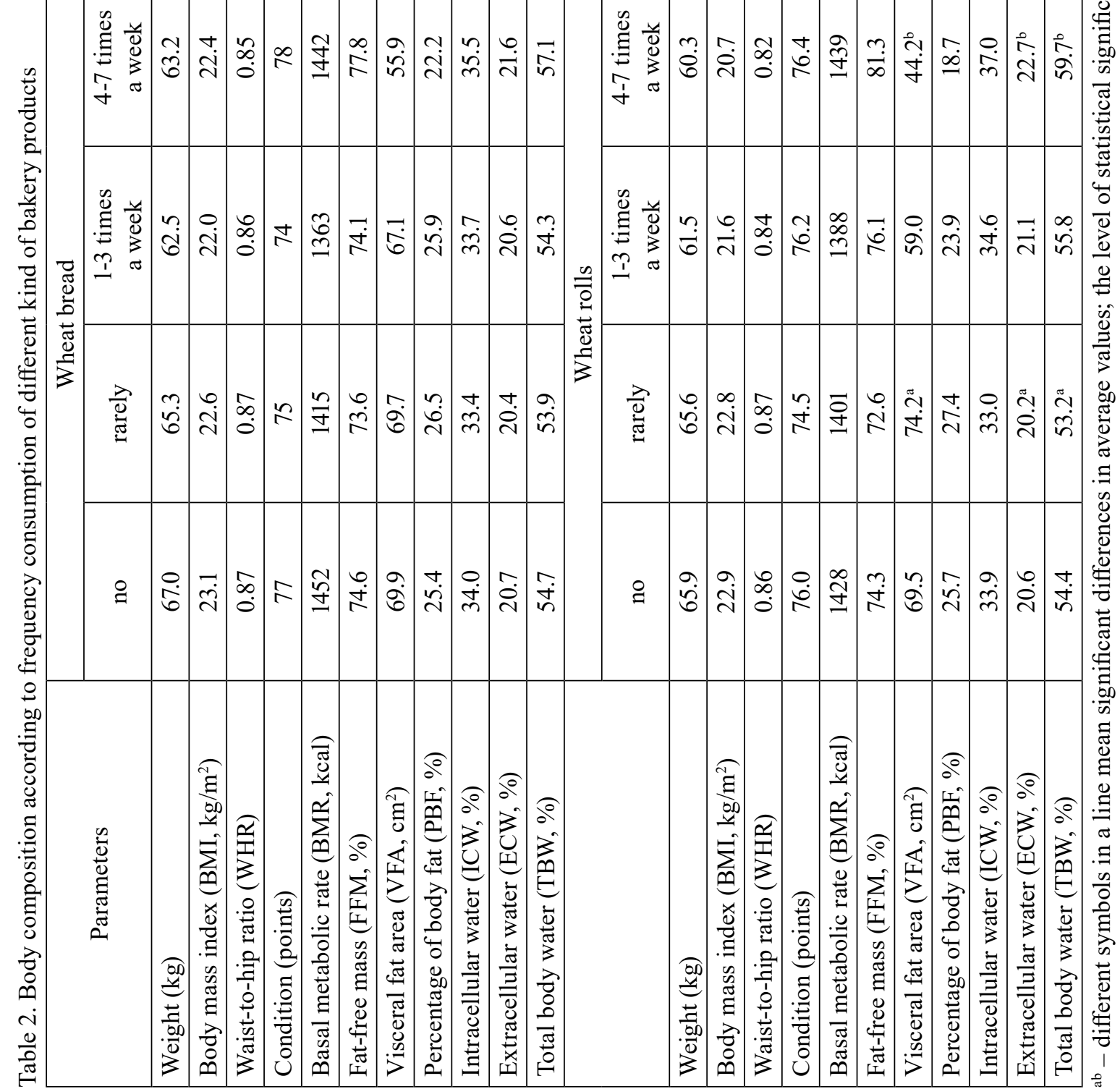




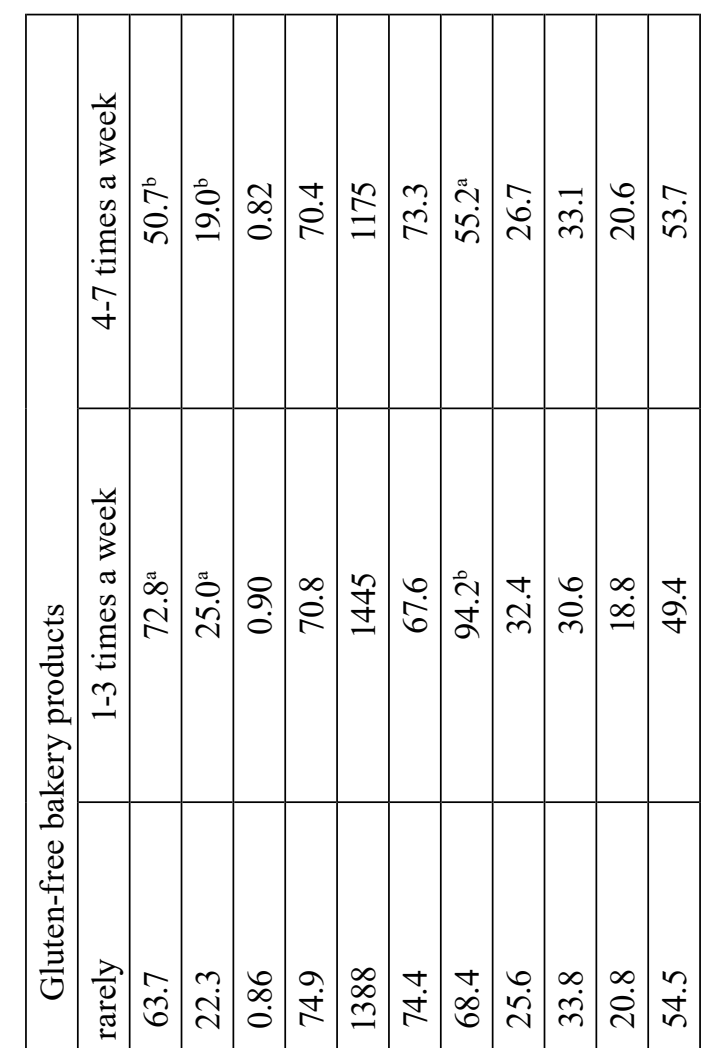

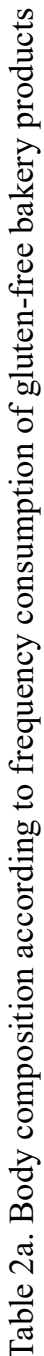

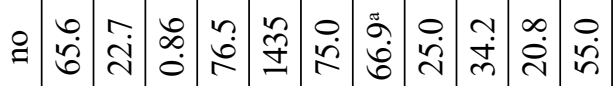

危

ำ

i

릉

\begin{tabular}{lll}
8 & $n$ \\
$\vdots$ & 0 \\
\hdashline & 1 \\
\hdashline & 0
\end{tabular}

竞。

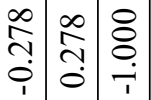

死

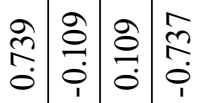

$\sum_{1} e^{\circ}$

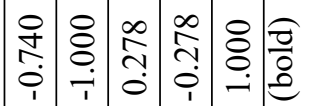

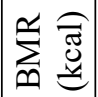

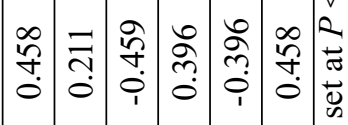

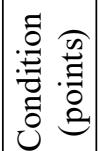

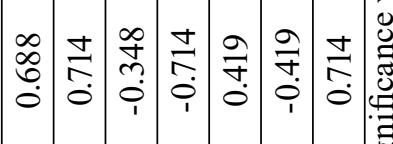

$\stackrel{\text { की }}{\frac{\pi}{3}}$

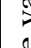

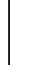

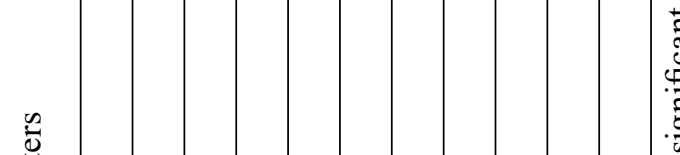

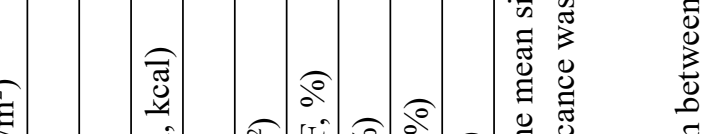

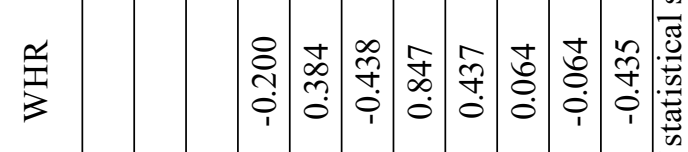

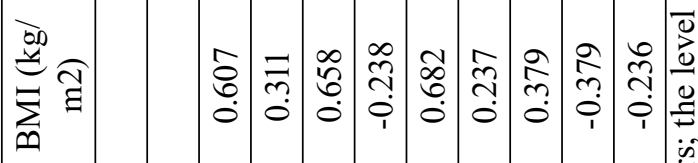

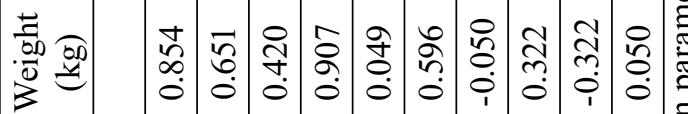

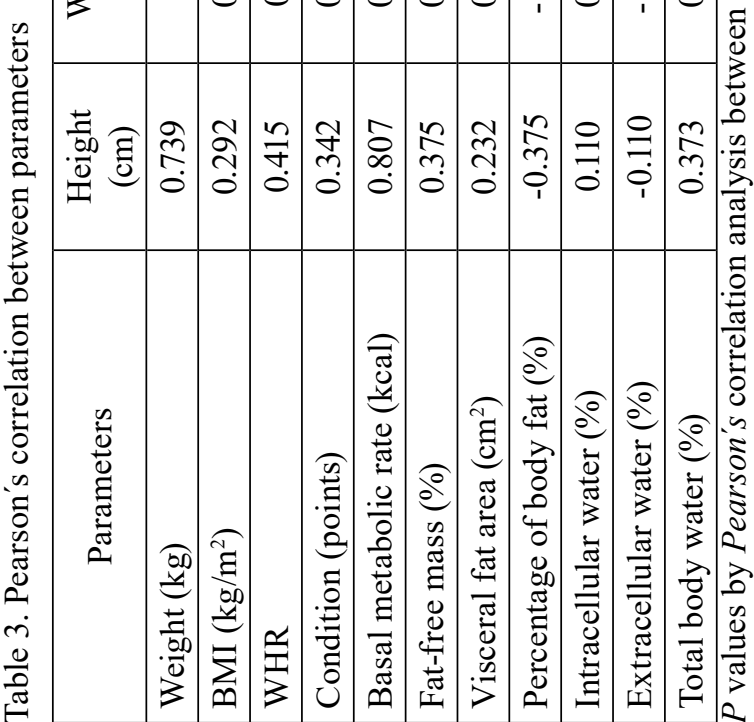


activity, which was reflected in the values of fitness, but also fat-free mass. We did not confirm the hypothesis that with increasing frequency of consumption of pastries, the values of obesity indicators increase.

Gluten-free products are intended for patients with celiac disease. In recent years, however, these products have become part of the diet of healthy people. Our results suggest that more frequent (1 to 3 times per week) consumption of gluten-free bakery products can cause weight gain. This is proved by the highest values of obesity and fat indicators (VFA, PBF, WHR, BMI). However, this group of consumers consisted of people who do not depend on strict gluten-free diet. People with gluten intolerance rely on the daily consumption of a gluten-free diet. This disease is associated with weight loss due to indigestion and poor utilization of nutrients. It is therefore necessary to take into account these possible factors influencing the results of the analysis, given that the group of consumers with the most frequent consumption had the lowest values of body weight, BMI, WHR, VFA $(\mathrm{P}<0.05)$. At the same time, these consumers had the worst level of physical activity and the lowest values of basal metabolism.

Based on the results, it can be stated that selected types of bread / bakery products play an important role in the regulation of body composition. The epidemiological model of obesity describes diet as the main causative agent of excess weight and scarce physical activity as the second main driver [7,31]. Our study suggests that low levels of physical activity and basal metabolism combined with intake of selected types of bread, especially wheat rolls, sweet pastries and gluten-free variants, may cause an increase in visceral as well as total body fat, BMI, weight gain, and this at the expense of a fat-free mass (especially muscle tissue). The level of physical activity must be taken into account when evaluating anthropometric parameters. In addition, when assessing the impact of consumption of different types of bread / bakery products on the values of anthropometric parameters and indicators of obesity, it is necessary to take into account not only the frequency of consumption, but also the amount of bakery product consumed. This is where we see the limitations of our survey. The results of our study show that the values of anthropometric parameters were significantly affected by the level of physical activity, because in most cases the best results were achieved by consumers with the most frequent consumption of the observed type of bread / bakery products, but also by the highest fitness values. At the same time, it is necessary to take into account the young and vital age of participants with relatively active metabolism, the absence of serious noninfectious disease and the absence of drug treatment affecting metabolic processes in the body.
Young adulthood (17-35 years) has become synonymous with the development of the wrong lifestyle associated with an increased risk of chronic diseases in later years $[42,67]$. Healthy dietary patterns are a global priority to reduce non-communicable diseases. In the study of Imamura et al. [32], better diets were seen in older adults compared with younger adults, and in women compared with men.

Similar findings were found by the authors Lee and Allen [41]. Men were overall more likely than young women to engage in negative eating habits. Consumption of ultraproccessed foods is continuously increasing and people with regularly physical activity is decreasing and becomes even less frequent with age [38].

Study in Poland showed that the frequency of whole-grain intake (including whole-grain bread) was not correlated with BMI and other body composition parameters. However, individuals who ate white bread (wheat, rye or wheat-rye bread, toast bread) less than once daily were characterized by lower visceral fat levels [39].

Many epidemiological studies have reported that higher intakes of whole grains are associated with a lower BMI, waist circumference and percent fat mass $[14,26,43]$. Increased intake of cereal fiber is associated with lower body weight and waist circumference over time [14]. Whole grains vary in their fiber and phytochemical content [11]. Oats and barley are high in the soluble fiber, while whole wheat is high in the insoluble fiber. For the health claims it is very important to know the different nutritional profiles of whole grains [11,14]. Kostecka et al. [39] found that consumption of whole-grain products did not affect the analyzed body composition parameters. Lower body fat percentage was observed only in women aged 18-39 who consumed whole-grain products once a day / several times a day.

Since 1975, obesity has almost tripled worldwide. More than 1.9 billion adults aged 18 and over were overweight in 2016, and more than 650 million were obese, meaning that $39 \%$ and $13 \%$ of adults were overweight or obese. In the same year, more than 340 million children and adolescents aged 5-19 suffered from overweight or obesity. In 2019, 38 million children under the age of 5 were overweight or obese [63].

BMI is associated with risk of comorbidities secondary to excess body fat $[18,30]$ and there is a large body of evidence correlating higher BMI with cardiometabolic disease such as diabetes $[1,57,58,61]$ and cardiovascular disease [54,66]. Dysfunction of adipose tissue plays a significant role in the genesis of metabolic disorders [4,23,27,59]. Decreasing body weight by $10 \%$ improves risk factors for chronic diseases [49]. 
BMI is limited for estimating body fat percentage and distribution. In addition to fat mass, the weight measurement incorporates lean mass, bone mass and fluid status. All of these body components contribute to weight independent of fat mass. To determine the degree to which the BMI value is indicative of excess adiposity, muscularity, volume status, sarcopenia, loss of muscle mass and other factors must be considering $[10,16,24]$. Age is one of the factor that may alter the functional significance of BMI at different ages. Adults tend to loose fat free mass and increase fat mass with increasing age [19]. Oedema can also affect the significance of BMI [64].

Waist circumference should be measured in all patients when evaluating for adiposity related disease risk. In many populations, a WC cut-off point of $\geq 94$ $\mathrm{cm}$ in men and $\geq 80 \mathrm{~cm}$ in women should be considered at risk and consistent with abdominal obesity [20]. Van Dijk et al. [60] found that both BMI and waist circumference were correlated with all cardiovascular disease risk factors. High waist circumference values, when the BMI is between 25 and $34.9 \mathrm{~kg} / \mathrm{m}^{2}$, are associated with an increased risk of type 2 diabetes, dyslipidemia, hypertension and cardiovascular disease. Over time, changes in waist circumference may indicate an increase or decrease in abdominal fat. Increase in abdominal fat is associated with an increased risk of heart disease [44]. Visceral fat has been associated with a greater cardiometabolic risk as compared with BMI [34].

Energy expenditure is an important component of maintaining a healthy weight. The guidelines for physical activity recommend at least 150 minutes of moderate physical activity or 75 minutes of vigorous physical activity per week, as well as muscle-strengthening activities at least twice per week for health benefits. Many factors affect obesity development, but one of the most important is an appropriate caloric intake and balance between energy intake and expenditure $[25,62]$.

A meta-analysis performed between 1980 and 2017 showed changes in physical activity from adolescence to young adulthood and showed a 13 to $17 \%$ decrease in physical activity with age [9]. The study of Tcymbal et al. [55] showed that young people aged 18-29 had low levels of physical activity. While only $18.9 \%$ did not meet WHO recommendations, in terms of total amount of physical activity and sedentary behavior they were closer to the oldest age group than to the 30-44-year-old group. The most active age group were people between 30 and 44 years old.

The study by Kerkadi et al. [36] revealed that physical inactivity, a sedentary lifestyle, and an unhealthy diet are factors that can increase weight and general or abdominal obesity.
The issue of obesity is still highly topical at present, also due to the fact that its prevalence is pandemic. There are many reasons for the emergence and maintenance of obesity, and attention should be paid not only to genetic predispositions, but especially to the lifestyle of an individual, specifically to its two components diet and physical activity. If there is a regular positive energy balance, either due to excessive energy intake (of course in the form of food) or insufficient energy expenditure, the emergence of overweight first, and later with the uneven trend, obesity is more than obvious. Blaming any food commodity for this condition is irrational. In the case of our intervention bakery products it should be added that while some types of pastries are considered healthier, especially in terms of fiber and other bioactive ingredients, we must not forget the fact that in the case of healthy food, not only its quality but also the quantity of intake is important. Replacing rafined bread with wholemeal bread can lead to a qualitative improvement in diet, but if the amount and time of consumption does not change, there may be an unfavorable trend in the development of body weight and other body composition parameters. Therefore, while adhering to the principles of rational diet focused on quality and quantity in diet, in combination with adequate physical activity, we will ensure not only optimal body weight, but also optimal overall body composition and active and full life.

\section{CONCLUSIONS}

A healthy diet, combined with moderate and regular physical activity, is a prerequisite for maintaining good health. Energy balance is an important part of preventing overweight or obesity. Therefore, it is important to pay attention to the correct selection of bakery products, their amount consumed and frequency of consumption. In our study, we observed among university students that groups of participants who did not consume a certain type of bread at all, rarely or 1 to 3 times a week, showed higher values of the examined parameters (BMI, body weight, body fat percentage, WHR) compared to a group that consumed a specific type of bread on average 4 to 7 times a week. The obtained values of the measured parameters of individual groups were largely influenced by the levels of physical activity and basal metabolism. Based on the findings we can conclude that while adhering to certain principles of healthy diet bakery products (within the prevalence of overweight and obesity) should not pose health risks to their consumers.

\section{Acknowledgement}

This publication was created thanks to support under the projects: Grant Agency of Faculty of 
Agrobiology and Food Resources SUA in Nitra (05GA FAPZ SPU-19); KEGA no. 004SPU-4/2019; Operational Programme Integrated Infrastructure for the projects: Long-term strategic research of prevention, intervention and mechanisms of obesity and its comorbidities (IMTS: 313011V344) and Demand-driven research for the sustainable and innovative food (Drive4SIFood 313011V336) cofinanced by the European Regional Development Fund.

\section{Conflict of interest}

The authors declare no conflict of interest.

\section{REFERENCES}

1. Abdullah, A., Peeters, A., de Courten, M., Stoelwinder, $J .:$ The magnitude of association between overweight and obesity and the risk of diabetes: a meta-analysis of prospective cohort studies. Diabetes Res Clin Pract. 2010;89(3):309-319. doi: 10.1016/j.diabres.2010.04.012

2. Abenavoli, L., Delibasic, M., Peta, V., Turkulov, V., Lorenzo, A.D., Medić-Stojanoska, M.: Nutritional profile of adult patients with celiac disease. European Review for Medical and Pharmacological Sciences 2015;19(22):4285-4292.

3. Andersen, G.S., Stunkard, A.J., Sørensen, T.I., Petersen, L., Heitmann, B.L.: Night eating and weight change in middle-aged men and women. Int $\mathrm{J}$ Obes Relat Metab Disord. 2004;28(10):1338-1343. doi: 10.1038/ sj.ijo.0802731

4. Bays, H.E.: Adiposopathy is "sick fat" a cardiovascular disease? J Am Coll Cardiol. 2011;57(25):2461-2473. doi: 10.1016/j.jacc.2011.02.038

5. Berkey, C.S., Rockett, H.R., Field, A.E., Gillman, M.W., Colditz, G.A.: Sugar-added beverages and adolescent weight change. Obes Res. 2004;12(5):778-788. doi: 10.1038/oby.2004.94

6. Bouchi, R., Asakawa, M., Ohara, N. et al.: Indirect measure of visceral adiposity 'A Body Shape Index' (ABSI) is associated with arterial stiffness in patients with type 2 diabetes. BMJ Open Diabetes Res Care 2016;4(1):e000188. doi: 10.1136/bmjdrc-2015-000188

7. Bray, G.A., Kim, K.K., Wilding, J.P.H.: Obesity: A chronic relapsing progressive disease process. A position statement of the World Obesity Federation. Obes. Rev. 2017;18:715-723. https://doi.org/10.1111/ obr.12551

8. Conte, P., Fadda, C., Piga, A., Collar, C.: Technofunctional and nutritional performance of commercial breads available in Europe. Food Science and Technology International 2016;22:621-633. doi: $10.1177 / 1082013216637724$

9. Corder, K., Winpenny, E., Love, R. et al.: Change in physical activity from adolescence to early adulthood: a systematic review and meta-analysis of longitudinal cohort studies. Br J Sports Med. 2019;53(8):496-503. doi: 10.1136/bjsports-2016-097330
10. De Lorenzo, A., Bianchi, A., Maroni, P. et al.: Adiposity rather than BMI determines metabolic risk. Int J Cardiol. 2013;166(1):111-117. doi: 10.1016/j.ijcard.2011.10.006

11. De Moura, F.F., Lewis, K.D., Falk, M.C.: Applying the FDA definition of whole grains to the evidence for cardiovascular disease health claims. J Nutr. 2009;139(11):2220S-2226S. doi: 10.3945/jn.109.112383

12. Decyk-Checel, A.: Children's and adolescents' eating habits. Probl Hig Epidemiol 2017;98(2):103-109.

13. Drewa, A., Zorena, K.: Prevention of overweight and obesity in children and adolescents in European countries. Pediatr Endocrinol Diabetes Metab 2017;23(3):152-158 doi:10.18544/PEDM-23.03.0087

14. Du, H., van $\operatorname{der} A$, D.L., Boshuizen, H.C. et al.: Dietary fiber and subsequent changes in body weight and waist circumference in European men and women. Am J Clin Nutr. 2010;91(2):329-336. doi: 10.3945/ajcn.2009.28191

15. Duffey, K.J., Gordon-Larsen, P., Jacobs, D.R.J., Williams, O.D., Popkin, B.M.: Differential associations of fast food and restaurant food consumption with 3-y change in body mass index: the Coronary Artery Risk Development in Young Adults Study. Am J Clin Nutr. 2007;85(1):201-208. doi: 10.1093/ajcn/85.1.201

16. Frankenfield, D.C., Rowe, W.A., Cooney, R.N., Smith, J.S., Becker, D.: Limits of body mass index to detect obesity and predict body composition. Nutrition 2001;17(1):26-30. doi: 10.1016/s0899-9007(00)00471-8

17. Fry, L., Madden, A.M., Fallaize, R.: An investigation into the nutritional composition and cost of gluten-free versus regular food products in the UK. Journal of Human Nutrition and Dietetics 2018;31(1):108-120. doi: $10.1111 / \mathrm{jhn} .12502$

18. Gallagher, D., Heymsfield, S.B., Heo, M., Jebb, S.A., Murgatroyd, P.R., Sakamoto, Y.: Healthy percentage body fat ranges: an approach for developing guidelines based on body mass index. Am J Clin Nutr. 2000;72(3):694-701. doi: 10.1093/ajen/72.3.694

19. Gallagher, D., Visser, M., Sepulveda, D., Pierson, R.N., Harris, T., Heymsfield, S.B.: How useful is body mass index for comparison of body fatness across age, sex, and ethnic groups? Am J Epidemiol. 1996;143(3):228239. doi: 10.1093/oxfordjournals.aje.a008733

20. Garvey, W.T., Mechanick, J.I., Brett, E.M., Garber, A.J., Hurley, D.L., Jastreboff, A.M., Nadolsky, K., PessahPollack, R., Plodkowski, R.: Reviewers of the AACE/ ACE Obesity Clinical Practice Guidelines. American Association of Clinical Endocrinologists And American College Of Endocrinology Comprehensive Clinical Practice Guidelines For Medical Care Of Patients With Obesity. Endocr Pract. 2016;22 Suppl 3:1203. doi: 10.4158/EP161365.GL

21. Gažarová, M., Lenártová, $\quad$ P.: Zmeny telesnej kompozície vplyvom konzumácie celozrnných pekárskych výrobkov. [Changes in body composition due to consumption of whole grain bakery products]. Nitra: Slovak University of Agriculture, 2020. $101 \mathrm{~s}$. ISBN 978-80-552-2283-7. In Slovak

22. Giacco, R., Della Pepa, G., Luongo, D., Riccardi, $G$. Whole grain intake in relation to body weight: From epidemiological evidence to clinical trials. Nutr 
Metab Cardiovasc Dis 2011;21:901-908. doi: 10.1016/j. numecd.2011.07.003

23. Giorgino, F.: Adipose tissue function and dysfunction: organ cross-talk and metabolic risk. Am J Physiol Endocrinol Metab. 2009;297(5):E975-E976. doi: 10.1152/ajpendo.00488.2009

24. Gómez-Ambrosi, J., Silva, C., Galofré, J.C. et al.: Body mass index classification misses subjects with increased cardiometabolic risk factors related to elevated adiposity. Int J Obes. 2012;36(2):286-294. doi: 10.1038/ ijo. 2011.100

25. Gonzalez-Campoy, J.M., St Jeor, S.T., Castorino, K., Ebrahim, A. etal.: Clinical practice guidelines for healthy eating for the prevention and treatment of metabolic and endocrine diseases in adults: cosponsored by the American Association of Clinical Endocrinologists/the American College of Endocrinology and the Obesity Society. Endocr Pract. 2013;19 Suppl 3:1-82. doi: 10.4158/EP13155.GL

26. Good, C.K., Holschuh, N., Albertson, A.M., Eldridge, A.L.: Whole grain consumption and body mass index in adult women: an analysis of NHANES 1999-2000 and the USDA pyramid servings database. J Am Coll Nutr. 2008;27(1):80-87. doi: 10.1080/07315724.2008.10719678

27. Goossens, G.H.: The role of adipose tissue dysfunction in the pathogenesis of obesity-related insulin resistance. Physiol Behav. 2008;94(2):206-218. doi: 10.1016/j. physbeh.2007.10.010

28. Guthold, R., Stevens, G.A., Riley, L.M. et al.: Worldwide trends in insufficient physical activity from 2001 to 2016: a pooled analysis of 358 population-based surveys with 19 million participants. Lancet Glob Health 2018;6(10):e1077-e1086. doi: 10.1016/S2214109X(18)30357-7

29. Hanson, N.I., Neumark-Sztainer, D., Eisenberg, M.E., Story, M., Wall, M.: Associations between parental report of the home food environment and adolescent intakes of fruits, vegetables and dairy foods. Public Health Nutr. 2005;8(1):77-85. doi: 10.1079/phn2005661

30. Heymsfield, S.B., Peterson, C.M., Thomas, D.M. et al.: Scaling of adult body weight to height across sex and race/ethnic groups: relevance to BMI. Am J Clin Nutr. 2014;100(6):1455-1461. https://doi.org/10.3945/ ajen.114.088831

31. Huang, H., Yan, Z., Chen, Y., Liu, F.: A social contagious model of the obesity epidemic. Sci Rep. 2016;28(6):37961. doi: 10.1038/srep37961

32. Imamura, F., Micha, R., Khatibzadeh, S. et al.: Dietary quality among men and women in 187 countries in 1990 and 2010: a systematic assessment. The Lancet Global Health 2015;3(3):e132-e142. doi: 10.1016/S2214109X(14)70381-X

33. Jensen, M.D., Ryan, D.H., Apovian,, C.M. et al.: 2013 AHA/ACC/TOS guideline for the management of overweight and obesity in adults: a report of the American College of Cardiology/American Heart Association Task Force on Practice Guidelines and The Obesity Society. Circulation 2014;129(25 Suppl 2):S10238. doi: 10.1161/01.cir.0000437739.71477.ee.

34. Kang, S.H., Cho, K.H., Park, J.W., Yoon, K.W., Do, J.Y.: Association of visceral fat area with chronic kidney disease and metabolic syndrome risk in the general population: analysis using multi-frequency bioimpedance. Kidney Blood Press Res. 2015;40(3):22330. doi: $10.1159 / 000368498$.

35. Katano, S., Nakamura, Y., Nakamura, A. et al.: Relationship between sleep duration and clustering of metabolic syndrome diagnostic components. Diabetes Metab Syndr Obes. 2011;4:119-125. doi: 10.2147/DMSO. S16147

36. Kerkadi, A., Sadig, A. H., Bawadi, H. et al.: The Relationship between Lifestyle Factors and Obesity Indices among Adolescents in Qatar. Int J Environ Res Public Health 2019;16(22):4428. doi: https://doi. org/10.3390/ijerph16224428

37. Kirwan, J.P., Malin, S.K., Scelsi, A.R. et al.: A WholeGrain Diet Reduces Cardiovascular Risk Factors in Overweight and Obese Adults: A Randomized Controlled In Trial. J Nutr. 2016;146(11):2244-2251. doi:10.3945/jn.116.230508

38. Kolotkin, R.L., Andersen, J.R.: A systematic review of reviews: Exploring the relationship between obesity, weight loss and health-related quality of life. Clin. Obes. 2017;7:273-289. https://doi.org/10.1111/cob.12203

39. Kostecka, M., Bojanowska, M., Kostecka, J., Ciolek, A.: An analysis of dietary patterns and body composition parameters in the Polish population. Rocz Panstw Zakl Hig. 2021;72(1):55-66. doi: 10.32394/rpzh.2021.0152

40.Lahey, R., Khan, S.S.: Trends in Obesity and Risk of Cardiovascular Disease. Curr Epidemiol Rep 2018;5(3):243-251. doi:10.1007/s40471-018-0160-1

41. Lee, J., Allen, J.: Gender Differences in Healthy and Unhealthy Food Consumption and Its Relationship with Depression in Young Adulthood. Community Mental Health Journal 2020. doi: 10.1007/s10597-020-00672-x

42.Liu, K., Daviglus, M.L., Loria, C.M. et al.: Healthy lifestyle through young adulthood and the presence of low cardiovascular disease risk profile in middle age: the coronary artery risk development in (Young) adults (CARDIA) study. Circulation 2012;125(8):996-1004. doi: 10.1161/CIRCULATIONAHA.111.060681

43. McKeown, N.M., Yoshida, M., Shea, M.K. et al.: Whole-grain intake and cereal fiber are associated with lower abdominal adiposity in older adults. J Nutr. 2009;139(10):1950-1955. doi: 10.3945/jn.108.103762

44. Messiah, S.: Body Composition. In: Gellman M.D. (eds) Encyclopedia of Behavioral Medicine. Springer, Cham [online], 2020. ISBN 978-3-030-39903-0. doi: https:// doi.org/10.1007/978-3-030-39903-0_728

45. Miranda, J., Lasa, A., Bustamante, M.A., Churruca, I., Simon, E.: Nutritional Differences Between a Glutenfree Diet and a Diet Containing Equivalent Products with Gluten. Plant Foods for Human Nutrition 2014;69:182187. doi: 10.1007/s11130-014-0410-4

46. Moyer, V.A., U.S. Preventive Services Task Force: Screening for and management of obesity in adults: U.S. Preventive Services Task Force recommendation statement. Ann Intern Med. 2012;157(5):373-8. doi: 10.7326/0003-4819-157-5-201209040-00475

47. Nakata, A.: Investigating the associations between work hours, sleep status, and self-reported health among full- 
time employees. Int J Public Health 2012;57:403-411. doi: 10.1007/s00038-011-0242-z

48. National Institute for Health and Care Excellence: Identification, assessment and management of overweight and obesity in children, young people and adults. (Clinical Guideline 189). Available at: http:// www.nice.org.uk/guidance/cg189. NICE: National Institute for Health and Care Excellence. 2014.

49. National Institutes of Health: Clinical Guidelines on the indentification, evaluation, and treatment of overweight and obesity in adults. The evidence report. Obes Res. 1998;6 Suppl 2:51S-209S.

50. Pol, K., Christensen, R., Bartels, E.M. et al.: Whole grain and body weight changes in apparently healthy adults: a systematic review and meta-analysis of randomized controlled studies. Am J Clin Nutr. 2013;98(4):872-884. doi:10.3945/ajcn.113.064659

51. Rolls, B.J., Roe, L.S., Meengs, J.S.: Larger portion sizes lead to a sustained increase in energy intake over 2 days. J Am Diet Assoc. 2006;106(4):543-549. doi: 10.1016/j. jada.2006.01.014

52. Romero-Corral, A., Somers, V.K., Sierra-Johnson, $J$. et al.: Accuracy of body mass index in diagnosing obesity in the adult general population. Int $\mathrm{J}$ Obes. 2008;32(6):959-966. doi: 10.1038/ijo.2008.11

53. Seger, J.C., Horn, D.B., Westman, E.C. et al.: Obesity Algorithm, presented by the American Society of Bariatric Physicians. Available at: www. obesityalgorithm.org. Obesity Medicine Association. 2015. Accessed May 13, 2021.

54. Strazzullo, P., D'Elia, L., Cairella, G., Garbagnati, F., Cappuccio, F.P., Scalfi, L.: Excess body weight and incidence of stroke: meta-analysis of prospective studies with 2 million participants. Stroke. 2010;41(5):e418-26. doi: 10.1161/STROKEAHA.109.576967

55. Tcymbal, A., Andreasyan, D., Whiting, S. et al.: Prevalence of Physical Inactivity and Sedentary Behavior Among Adults in Armenia. Frontiers Public Health 2020;8:157. doi: https://doi.org/10.3389/ fpubh.2020.00157

56. The GBD 2015 Obesity Collaborators: Health Effects of Overweight and Obesity in 195 Countries over 25 Years. N Engl J Med 2017;377(1):13-27. doi: 10.1056/ NEJMoa1614362

57. Tobias, D.K., Pan, A., Jackson, C.L. et al.: Body-mass index and mortality among adults with incident type 2 diabetes. N Engl J Med. 2014;370(3):233-244. doi: 10.1056/NEJMoa1304501

58. Twig, G., Afek, A., Derazne, E. et al.: Diabetes risk among overweight and obese metabolically healthy young adults. Diabetes Care. 2014;37(11):2989-2995. doi: $10.2337 / \mathrm{dc} 14-0869$
59. van de Woestijne, A.P., Monajemi, H., Kalkhoven, E., Visseren, F.L.: Adipose tissue dysfunction and hypertriglyceridemia: mechanisms and management. Obes Rev. 2011;12(10):829-840. doi: 10.1111/j.1467789X.2011.00900.x

60. van Dijk, S.B., Takken, T., Prinsen, E.C., Wittink, H.: Different anthropometric adiposity measures and their association with cardiovascular disease risk factors: a meta-analysis. Neth Heart J. 2012;20(5):208-218. doi: 10.1007/s12471-011-0237-7

61. Vazquez, G., Duval, S., Jacobs, D.R., Silventoinen, K.: Comparison of body mass index, waist circumference, and waist/hip ratio in predicting incident diabetes: a meta-analysis. Epidemiol Rev. 2007;29:115-128. doi: 10.1093/epirev/mxm008

62. WHO: Global recommendations on physical activity for health. Geneva 2010. Available https://apps.who.int/iris/ bitstream/handle/10665/44399/9789241599979_eng. pdf?sequence $=1$ (Accessed 10.05.2021)

63. WHO: Obesity and overweight. Available https://www. who.int/news-room/fact-sheets/detail/obesity-andoverweight (Accessed 13.05.2021).

64. Woodruff, B.A., Duffield, A.: Anthropometric assessment of nutritional status in adolescent populations in humanitarian emergencies. Eur J Clin Nutr. 2002;56(11):1108-1118. doi: 10.1038/sj.ejcn.1601456

65. World Health Organization Expert Committee: Physical status: the use and interpretation of anthropometry. Report of a WHO Expert Committee. World Health Organ Tech Rep Ser. 1995;854:1-452.

66. Wormser, D., Kaptoge, S., Di Angelantonio, E. et al.: Emerging Risk Factors Collaboration. Separate and combined associations of body-mass index and abdominal adiposity with cardiovascular disease: collaborative analysis of 58 prospective studies. Lancet 2011;377(9771):1085- 1095. doi: 10.1016/S01406736(11)60105-0

67. Zheng, Y., Manson, J. E., Yuan, Ch. et al.: Associations of Weight Gain From Early to Middle Adulthood With Major Health Outcomes Later in Life. JAMA 2017;318(3):255-269. doi:10.1001/jama.2017.7092

68. Zuccotti, G., Fabiano, V., Dilillo, D., Picca, M., Cravidi, $C$., Brambilla, $P$.: Intakes of nutrients in Italian children with celiac disease and the role of commercially available gluten-free products. Journal of Human Nutrition and Dietetics 2013;26(5):436-444. doi: 10.1111/jhn.12026

Received: 18.05.2021

Accepted: 21.06.2021

Published online first: 28.06.2021 